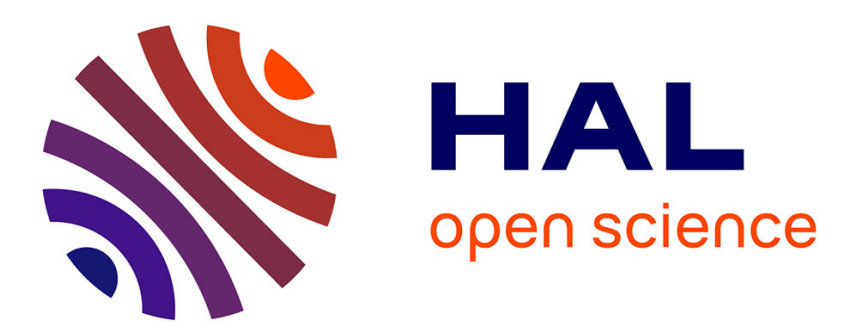

\title{
On-line monitoring of the transesterification reaction carried out in microreactors using near infrared spectroscopy
}

Romain Richard, Brigitte Dubreuil, Sophie Thiebaud-Roux, Laurent E. Prat

\section{- To cite this version:}

Romain Richard, Brigitte Dubreuil, Sophie Thiebaud-Roux, Laurent E. Prat. On-line monitoring of the transesterification reaction carried out in microreactors using near infrared spectroscopy. Fuel, 2013, vol. 104, pp. 318-325. 10.1016/j.fuel.2012.07.054 . hal-00782855

\section{HAL Id: hal-00782855 \\ https://hal.science/hal-00782855}

Submitted on 30 Jan 2013

HAL is a multi-disciplinary open access archive for the deposit and dissemination of scientific research documents, whether they are published or not. The documents may come from teaching and research institutions in France or abroad, or from public or private research centers.
L'archive ouverte pluridisciplinaire HAL, est destinée au dépôt et à la diffusion de documents scientifiques de niveau recherche, publiés ou non, émanant des établissements d'enseignement et de recherche français ou étrangers, des laboratoires publics ou privés. 


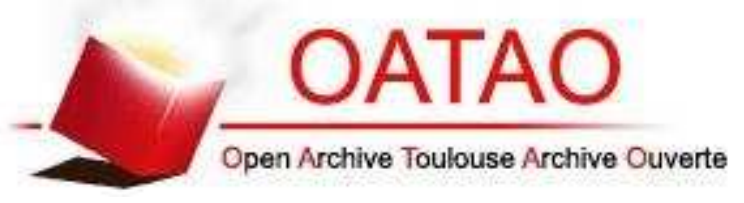

Open Archive Toulouse Archive Ouverte (OATAO)

OATAO is an open access repository that collects the work of Toulouse researchers and makes it freely available over the web where possible.

This is an author-deposited version published in: http://oatao.univ-toulouse.fr/ Eprints ID: 7891

To link to this article: DOI:10.1016/j.fuel.2012.07.054

http://dx.doi.org/10.1016/j.fuel.2012.07.054

\section{To cite this version:}

Richard, Romain and Dubreuil, Brigitte and Thiebaud-Roux, Sophie and Prat, Laurent E. On-line monitoring of the transesterification reaction carried out in microreactors using near infrared spectroscopy. (2013) Fuel, vol. 104. pp. 318-325. ISSN 0016-2361

Any correspondence concerning this service should be sent to the repository administrator: staff-oatao@inp-toulouse.fr 


\section{On-line monitoring of the transesterification reaction carried out in microreactors using near infrared spectroscopy}

Romain Richard $^{\mathrm{a}, \mathrm{b}, \mathrm{c}, \mathrm{d}}$, Brigitte Dubreuil ${ }^{\mathrm{a}, \mathrm{b}}$, Sophie Thiebaud-Roux ${ }^{\mathrm{a}, \mathrm{b},{ }^{*}, \text { Laurent Prat }}{ }^{\mathrm{c}, \mathrm{d}}$

${ }^{a}$ Université de Toulouse, INP-ENSIACET, LCA (Laboratoire de Chimie AgroIndustrielle), F-31030 Toulouse, France

${ }^{\mathrm{b}}$ INRA, UMR 1010 CAI, F-31030 Toulouse, France

${ }^{\mathrm{c}}$ Université de Toulouse ; INP, UPS ; Laboratoire de Génie Chimique ; 4, allée Emile Monso, F-31030 Toulouse cedex 4, France

${ }^{\mathrm{d}}$ CNRS ; Laboratoire de Génie Chimique ; F-31030 Toulouse, France

* Corresponding author: Sophie Thiebaud-Roux

INPT-ENSIACET, Laboratoire de Chimie Agroindustrielle, 4 allée Emile Monso, BP 44362, 31030

Toulouse cedex 4, France

E-mail: sophie.thiebaudroux@ensiacet.fr

Tel: (33) 5343235 04; Fax: (33) 534323597. 


\begin{abstract}
Biodiesel can be produced from vegetable oils, animal fats, and waste cooking oils by transesterification with ethanol (also called ethanolysis) in order to substitute fossil fuels. In this work, the batch ethanolysis of high oleic sunflower oil was transferred into a continuous microstructured device, which induces a better control of heat and mass transfers. Various parameters were studied, notably the initial ethanol to oil molar ratio. An innovative method using NIR spectroscopy was also developed to on-line monitor the transesterification reaction of high oleic sunflower oil with ethanol in microreactors (circular PFA tube 1/16" OD, 0.02" ID). The reactions were monitored directly in the microreactors through sequential scans of the reaction medium by the means of an adequate probe. The asset of the method is that no sample collection or preparation is necessary. Partial least squares regression was used to develop calibration and prediction models between NIR spectral data and analytical data obtained by a reference method (gas chromatography with flame ionization detection, GC-FID). This method is fast, safe, reliable, non destructive and inexpensive contrary to conventional procedures, such as gas chromatography and high performance liquid chromatography generally used to determine the composition of crude transesterification medium.
\end{abstract}

\title{
Keywords
}

Biodiesel; Transesterification; Microreactors; Near InfraRed (NIR) spectroscopy; Ethanol 


\section{Introduction}

Biodiesel can be produced from vegetable oils, animal fats, and waste cooking oils by transesterification [1, 2] with an alcohol (alcoholysis) in order to substitute fossil fuels. Many works have used methanol [3-6] as alcohol reactant which is mainly produced by oxidation processes of methane, a natural gas component, hence a nonrenewable energy. Ethanol and particularly bioethanol from sugar cane, sugar beet or corn is preferable to methanol due to its superior dissolving power for vegetable oils, low toxicity and its renewable origin. However, using ethanol leads to additive problems which have to be overcome to obtain a profitable process. First of all, its reactivity is slightly less important as it is less acidic than methanol because of a longer carbon chain. Besides, fatty acid ethyl esters (FAEE) production using ethanol is more costly than fatty acid methyl esters (FAME) production with methanol, due to a process composed of more steps using, particularly, a refill with ethanol and catalyst, when the reaction equilibrium is reached, in order to shift it.

Various other factors such as free fatty acid (FFA) content, water content, type/amount of catalyst, vegetable oil to alcohol molar ratio, or temperature [3, 7-9] can affect the process. This transesterification leads to high conversion of triglycerides (TG) into ethyl esters [10] with diglycerides (DG) and monoglycerides (MG) as reaction intermediates and glycerol as by-product (reaction in three consecutive steps). Ethanolysis is generally conducted in batch reactors. Depending on the reactional scheme and the thermokinetic properties of the system, continuous processes may withdraw existing obstacles of batch processes such as numerous steps, secondary reactions, stable equilibria and difficulties to separate the reaction products. Several works on biodiesel production using microreactors have recently been published [1114]. The methanolysis system is complex due to changing phase equilibria [15]: two 
immiscible phases are present at the beginning (vegetable oil and methanol), then a single phase appears after a few minutes of reaction. Finally, two phases are obtained at the end of the reaction, majorly composed of methyl esters and glycerol. Moreover, this reaction involves simultaneous phenomena (mixing, heat and mass transfers) which have to be precisely controlled. Hence, to properly design a continuous process, numerous data are required. In this study, we transferred the batch ethanolysis of high oleic sunflower oil into a continuous microstructured device. Indeed, microreactors generally induce a better control of heat and mass transfers. Furthermore, process intensification using microreactors is less costly due to reduced equipment size and lower reactant consumption [16]. To extrapolate microstructured continuous processes, a numbering-up approach is chosen as it is faster and easier than a scale-up approach, generally used in batch processes.

Many analytical procedures have been developed to determine the composition of crude transesterification products. In previous studies, different analytical methods such as gas chromatography $[17,18]$, high performance liquid chromatography [19], Fourier transform infrared spectroscopy $[20,21]$ have been developed to off-line monitor the composition of reaction mixtures (FFA, ethyl esters, MG, DG, TG, glycerol) obtained during or after transesterification of vegetable oils with ethanol. Nevertheless, these techniques are long to handle and expensive. They generally require special training, samples collection and involve solvent for sampling preparation. Up to now, only a few works with different analytical techniques such as mid-infrared (MIR) spectroscopy [22, 23], near infrared (NIR) spectroscopy [24-27], Raman spectroscopy [28], ultrasonication-assisted spray ionization mass spectroscopy [29], fluorescence [30] or UV spectroscopy [31] are able to on-line monitor organic reactions (mostly different 
from transesterification reaction). With these methods, process state can be obtained from whole sample finger-printing.

Faced to all these analytical techniques, we decided to on-line monitor the transesterification reaction of high oleic sunflower oil with ethanol in microreactors (circular polyfluoro alkoxy (PFA) tube 1/16"OD, 0.02'ID) using NIR spectroscopy, which is an innovative method for this type of reaction in such a process. NIR spectroscopy with multivariate analysis is a well-established, fast, reliable, inexpensive and non-destructive analytical technique, and does not require complex pre-treatment [32-34]. Among the various parameters which can be investigated, the initial ethanol to oil molar ratio was studied in this work. The reactions in the microreactors were monitored through sequential scans of the reaction medium with an adequate probe. Partial Least Squares (PLS) regression was used to develop calibration models between NIR spectral data and analytical data obtained by a reference method: gas chromatography with flame ionization detection (GC-FID). The developed models were validated by comparison with GC data.

\section{Material and methods}

2.1. Material and reagents

High oleic sunflower oil (97.9\% TG, 1.6\% DG and 0.5\% FFA) was obtained from ITERG (Pessac, France). Its fatty acid composition (\% by weight) is as follows: $3.5 \%$ palmitic acid, 3.0\% stearic acid, $87.6 \%$ oleic acid, $4.9 \%$ linoleic acid and $1.2 \%$ other acids. Hydrochloric acid (analytical quality, 37\% solution in water) and sodium ethoxide EtONa (analytically pure, $21 \mathrm{wt} \%$ in ethanol) were purchased from Acros Organics; absolute ethanol (99.95\%) and cyclohexane (HPLC grade) were supplied by Scharlau. 
N-methyl-N-trimethylsilyl-heptafluorobutyramide (MSHFBA) and methylimidazole (MI) were purchased respectively from Macherey Nagel and Sigma-Aldrich.

\subsection{Transesterification reaction}

The transesterification reaction was performed in circular PFA tubes. These tubes were submerged in a temperature-controlled water bath to maintain the targeted microreactor temperature. As in batch processes, temperature was maintained at $65{ }^{\circ} \mathrm{C}$, close to the boiling point of ethanol $\left(78^{\circ} \mathrm{C}\right)$ but lower than $70^{\circ} \mathrm{C}$ in order to avoid the formation of ethanol boiling bubbles. Transesterification of high oleic sunflower oil was carried out by using the following procedure: liquids (oil and EtOH/EtONa mixture) were injected by syringe-pumps with perfect flow rate control. Several ethanol to oil molar ratios were tested $(45.4,22.7,16.2,9.0$ and 6.0) with the same amount of catalyst ( $1 \mathrm{wt} \%$ compared to oil mass) and the same water content in ethanol $(0.08 \mathrm{wt} \%$, determined by Karl-Fisher titration). After mixing in a T-junction, the reaction medium flows into the tube. With constant flow rates, each tube length corresponds to a reaction time. A $2 \mathrm{~m}$-length tube was used, which is equivalent to a reaction time of $16 \mathrm{~min}\left(\mathrm{~F}_{\text {tot }}\right.$ $=1.5 \mathrm{~mL} / \mathrm{h}$ and $\mathrm{U}_{\text {tot }}=2.12 \mathrm{~mm} / \mathrm{s}$ ). Maintaining the same flow rates, the tube was cut in order to obtain lower reaction times. Samples were collected during $15 \mathrm{~min}$. The reaction was quenched by neutralizing the alkali catalyst with a concomitant addition of $\mathrm{HCl}(3.7 \%$ solution in water) at a constant flow rate. For each collected sample, the medium composition at different reaction times was determined by using GC-FID analysis. In the meanwhile, NIR spectroscopy was performed at the same reaction times as the sample collection in order to on-line monitor the transesterification reaction (see Fig. 1). 


\subsection{Gas chromatography analysis}

The collected samples were analyzed by gas chromatography using a Perkin Elmer Instrument (Perkin Elmer, USA) coupled to a flame ionization detector (FID). Separation was carried out with a silica capillary column (CP-Sil 8 CB lowbleed/MS, $5 \%$ phenyl $+95 \%$ dimethylpolysiloxane, $15 \mathrm{~m}, 0.32 \mathrm{~mm}, 0.25 \mu \mathrm{m}$ ) from Varian (USA). The chromatograph was equipped with an automatic injector and the injections $(1 \mu \mathrm{L})$ were performed with an "on-column” system.

The carrier gas was helium (Air Liquide, France) and the column head pressure was adjusted to 15 psi. Injector temperature was $55{ }^{\circ} \mathrm{C}$ during $0.5 \mathrm{~min}$ and ramped to $340{ }^{\circ} \mathrm{C}$ at $200{ }^{\circ} \mathrm{C} / \mathrm{min}$ (held $43 \mathrm{~min}$ ). Temperature in the oven was held $0.5 \mathrm{~min}$ at $55^{\circ} \mathrm{C}$, then ramped to $80{ }^{\circ} \mathrm{C}$ at $45^{\circ} \mathrm{C} / \mathrm{min}$ and finally increased to $360{ }^{\circ} \mathrm{C}$ at $10{ }^{\circ} \mathrm{C} / \mathrm{min}$ (held $16 \mathrm{~min}$ ). The total running time was $45 \mathrm{~min}$. The temperature of the detector (FID) was $360{ }^{\circ} \mathrm{C}$.

All the samples $(180 \mu \mathrm{L})$ were previously silylated with $20 \mu \mathrm{L}$ of a mixture of MSHFBA $(1 \mathrm{~mL})$ and MI $(50 \mu \mathrm{L})$. This hydroxyl group silylation is intended to increase volatility and stability of the hydroxy compounds injected, and therefore to improve their detection. Cyclohexane was used as solvent to prepare standard solutions and heptadecane was used as an internal standard $(1 \mathrm{mg} / \mathrm{mL})$.

With this analytical procedure, molar concentrations of ethyl oleate, oleic acid, monoglycerides, diglycerides and triglycerides in the different phases resulting from the reaction were determined. The gas chromatography data was used to calculate the total ethyl ester (more precisely ethyl oleate) content in oleic chains mixture:

Ethyl Ester Content $(\%)=\frac{[\mathrm{EE}]_{\mathrm{t}}}{[\mathrm{EE}]_{\mathrm{t}}+\left[\mathrm{C}_{18: 1}\right]_{\mathrm{t}}+[\mathrm{MG}]_{\mathrm{t}}+2 \times[\mathrm{DG}]_{\mathrm{t}}+3 \times[\mathrm{TG}]_{\mathrm{t}}}$ 
where $[\mathrm{EE}]_{\mathrm{t}},\left[\mathrm{C}_{18: 1}\right]_{\mathrm{t}},[\mathrm{MG}]_{\mathrm{t}},[\mathrm{DG}]_{\mathrm{t}}$ and $[\mathrm{TG}]_{\mathrm{t}}$ represent respectively the molar concentrations $(\mu \mathrm{mol} / \mathrm{mL})$ of ethyl oleate, oleic acid and oleic monoglycerides, diglycerides and triglycerides at a given time $\mathrm{t}$.

\subsection{NIR spectroscopy analysis}

The NIR spectra of the transesterification reaction mixture samples were recorded by averaging 32 scans (approximately 1s/scan) in the wavenumber range of 10,000$4000 \mathrm{~cm}^{-1}$ using a NIR spectrometer (Antaris MX FT-NIR Process Analyzer from Thermo Fisher Scientific, USA). This apparatus can be equipped with two different fiber-optic probes (presented in Fig. 2). One works by reflection (QR200-7-VIS/NIRBX from Ocean Optics, USA) whereas the other works by transflectance (Series 625 Single Fiber Translectance Probe, $\mathrm{L}=18$ ", $\mathrm{d}=0.5$ " from Thermo Scientific, USA). With the latter, the beam passes through the PFA tube and the solution, then reflects on a mirror, before passing again through the solution and the PFA tube. The optical beam path was $3 \mathrm{~mm}$ (twice the tube diameter) and the spectral resolution was $2 \mathrm{~cm}^{-1}$. The spectrometer was operated by Omnic software (Thermo Fisher Scientific, USA). Before statistical analysis, the NIR spectrum of the empty PFA tube before reaction (without reactants) was subtracted from the NIR spectra of the transesterification reaction mixtures.

\subsection{Statistical analysis}

TQ Analyst software (Thermo Fisher Scientific, USA) was used to import and analyze the data. Each NIR spectrum corresponds to a reaction aliquot which was collected and analyzed by GC-FID. The NIR analyses were not performed on the total 
wavenumber range of NIR spectra $\left(10,000-4000 \mathrm{~cm}^{-1}\right)$ because several regions were not useful for data treatment. Thus, three different spectral regions were suggested by TQ Analyst software to improve the results of the statistical treatment: from 8649 to $8085 \mathrm{~cm}^{-1}, 7097$ to $5508 \mathrm{~cm}^{-1}$ and 5050 to $4476 \mathrm{~cm}^{-1}$. Significant spectral variations were observed in these regions when different ethanol to oil molar ratios were used.

A series of ethanol to oil molar ratios (from 6.0 to 45.4 ) were tested in the transesterification reaction at $65{ }^{\circ} \mathrm{C}$. Samples were collected at different reaction times (from $47 \mathrm{~s}$ to $16 \mathrm{~min}$ ). Moreover, the experiment at a molar ratio of 45.4 was repeated 5 times. Thus a total of 130 samples were available for data treatment.

Partial Least Squares (PLS) regression was used to develop calibration models between spectral and analytical GC data. This method is quantitative. The values of ethyl oleate contents were used to establish a multivariate model with the NIR spectra. In order to remove small inter-microreactor differences due to uncontrolled variation sources, data pre-processing methods were applied to the spectra, such as baseline correction, Savitzky-Golay smoothing, first or second derivative, mean centering, variable scaling and also variables selection. Root Mean Square Error on Calibration (RMSEC) and Root Mean Square Error on Prediction (RMSEP) were used to evaluate the performance of the method. The closer the RMSE value is to zero, the smaller are the differences between the calculated concentrations values and the actual values.

From PLS regression, two calibration models were developed. The first model is able to predict variations of the ethyl oleate content in the reaction mixtures with the ethanol to oil molar ratio varying from 6.0 to 45.4 . We used 69 samples for this model: 44 for calibration and 25 for validation. Besides, an other calibration model was developed from the spectra of the set of 61 samples ( 40 for the calibration and 21 for the external validation), all measured at $65{ }^{\circ} \mathrm{C}$ for an ethanol to oil molar ratio of 45.4 , to predict the content of the main chemical component: ethyl oleate. 


\section{Results and discussion}

3.1. Comparison of transesterification reaction kinetics in batch and continuous processes (microreactors)

\subsubsection{Batch transesterification}

The reaction was previously performed in a $1 \mathrm{~L}$-batch reactor for several ethanol to oil molar ratios at $70{ }^{\circ} \mathrm{C}$ [34]. The mechanical stirring speed was $750 \mathrm{rpm}$ in order to have a satisfactory mixing in the batch reactor. The minimum water content in ethanol $(0.08 \%)$ was used in this work because the presence of water causes hydrolysis of EtONa into $\mathrm{NaOH}$ and $\mathrm{EtOH}$ but also ester saponification resulting in the formation of FFA (after neutralization of each sample by $\mathrm{HCl}$ addition). For example, no FFA was obtained with $0.08 \%$ water content whereas FFA content increases to nearly $3 \%$ with 5.54\% water content. Moreover, the ester formation nearly decreased by half between water contents of $0.08 \%$ and $5.54 \%$. This ester content decrease is not only due to the secondary reactions but also to a decrease of intersolubility of transesterification reactants. This means that the solubility of ethanol in TG, DG or MG decreases when the water content in ethanol increases, which involves a lower reactivity of these glycerides with ethanol.

Ethyl oleate contents at different reaction times have been obtained by GC-FID. The results for three different ethanol to oil molar ratios (3.0, 6.0 and 9.0) are presented in Table 1.

According to previous works [35], the use of high ethanol to oil molar ratio results in greater ester formation in a shorter time. As shown in Fig. 3, the ethyl oleate content 
reached $99.5 \%$ when the molar ratio was set at a value of $6: 1$. Even though the stoichiometric ratio for transesterification requires three moles of alcohol for one mole of triglycerides to yield three moles of fatty acid alkyl esters and one mole of glycerol, higher molar ratios of alcohol to vegetable oil are usually used to enhance the solubility of glycerides in alcohol and to increase the contact surface between these compounds. It can be inferred that at molar ratios inferior to $6: 1$, the reaction is incomplete due to solubility diagrams [36]. At higher molar ratios than 6:1, the ethyl oleate content decreases slightly for a given reaction time. This can be explained by the dilution effect but also by the increase of glycerol content in the ester-rich phase. Indeed, the separation of glycerol from the ester-rich phase becomes more difficult as the ethanol amount increases [8], driving the equilibrium back to the reactants, resulting in a lower ethyl oleate content.

It can be noticed that all the reactions reach equilibrium after about $20 \mathrm{~min}$. Only few information on kinetics are available for the low reaction times. In order to get more data as soon as the reaction starts, this reaction was carried out in a continuous system constituted by microreactors.

\subsubsection{Continuous transesterification processes in microreactors}

For the implementation of the reaction in continuous at microscale, some operating conditions have to be carefully chosen. Higher ethanol to oil molar ratios will be prefered in microreactors to avoid soap formation in case of water and FFA presence. This soap generates an increase of medium viscosity and formation of gels $[37,38]$ if the amount of ethanol is too low (case of ethanol:oil $=3: 1$ ). The viscosity increase can stop the reagents flows and has to be avoided. Furthermore, temperature was set at $65^{\circ} \mathrm{C}$ because $70{ }^{\circ} \mathrm{C}$ was too close the boiling point of ethanol (some bubbles appear at 
$70{ }^{\circ} \mathrm{C}$ ). A coflowing jet with oil as the internal fluid and ethanol as the external fluid was chosen.

The advantages expected at microscale are linked to (i) the very high surface/volume $(\mathrm{S} / \mathrm{V})$ ratio which increases heat and mass transfer; (ii) the control of the initial mixing time which does not depend on the feeding procedure; (iii) the possibility to make measurements at the very beginning of the kinetics. This last point is of course of particular interest when coupled with on-line measurement.

In the case of the reaction mixtures with varying ethanol to oil molar ratio from 6.0 to 45.4 in microreactors, the reflection probe was used to collect the NIR data. The total ethyl oleate contents obtained by GC-FID according to the reaction time are illustrated in Fig. 4 (corresponding data are available in Table 1).

According to Fig. 4, the highest molar ratios (16.2 to 45.4) accelerate the reaction rate at the beginning of the reactions. This can be explained by confinement in microreactors: higher ethanol to oil molar ratios involve $\mathrm{S} / \mathrm{V}$ ratio increase $\left(\mathrm{S} / \mathrm{V}=2 / \mathrm{r}_{\mathrm{oil}}\right.$ with $r_{\text {oil }}$ the oil phase radius in the tube). Besides, a radial concentration gradient of oil in the ethanol reactive phase results from higher molar ratios: with more ethanol, oil concentration in ethanol phase decreases, which induces an increase of oil transfer. Hence these both phenomena involve better mass and heat fluxes and therefore better reactivity. Otherwise, the evolutions of reaction intermediates (MG and DG) are different for each molar ratio. For example, the DG content reaches $7.2 \%$ after $2 \mathrm{~min}$ and then decreases to less than $0.1 \%$ after $15 \mathrm{~min}$ for the 45.4 ratio, whereas it reaches $14.4 \%$ after 2 min and then decreases to $2.0 \%$ for the 6.0 ratio. A maximum MG content is reached for the different ratio but the final content is $1.8 \%$ and $6.2 \%$ for respectively the 45.4 and 6.0 ratios. Hence, the conversion of reaction intermediates (MG and DG) was faster with higher ethanol to oil molar ratios, in agreement with the faster formation of ethyl oleate. 
Concerning the experiment with constant ethanol to oil molar ratio of 45.4, the NIR data were collected with the transflectance probe in order to show the reproducibility of the experiment. Five experiments were carried out and showed satisfactory reproducibility (see following data treatment).

\subsection{Partial Least Squares regressions (PLS)}

Concerning the PLS regressions, only ethyl oleate content has been predicted because it is the only compound of the medium of which the content covers all the range between $0 \%$ and $100 \%$ with many points. Besides, PLS regressions on contents of other compounds such as oleic acid, MG, DG and TG were not performed because their concentration ranges were too limited to establish a valuable predicting model. Indeed, Fig. 5 shows that the content range of oleic acid, MG and DG varies from $0 \%$ to $11 \%$.

Several pre-processing methods have been performed on the NIR spectra before applying the PLS regression: a baseline correction, a Savitzky-Golay smoothing, first derivative, mean-centering and variable scaling. Results are shown in Table 2.

Data pre-processing methods lead to better RMSEC and RMSEP values. Five latent variables for ethyl oleate have been used to build the PLS model for predicting ethyl oleate contents of the reaction mixture obtained with different ethanol to oil molar ratios. The predicted contents of ethyl oleate obtained during transesterification show no significant differences with the chromatographic results as shown in Fig. 6. Indeed the correlation coefficient $\left(\mathrm{R}^{2}\right)$ was 0.985 , whereas the RMSEC and RMSEP were respectively $4.08 \%$ and $4.10 \%$.

Another calibration model was developed by using only experiments with an ethanol to oil molar ratio of 45.4. The calibration plot for ethyl oleate content (Fig. 7) 
shows a good correlation of $\mathrm{R}^{2}=0.983$ using nine latent variables. More latent variables are needed here for several reasons:

(i) the calibration and validation sample sets are too small, in particular for the lower ester contents,

(ii) with the transflectance probe, the tube may not be in exactly the same position for all data acquisition, which may change the optical beam path,

(iii) the tube absorbs a part of the optical beam and even if the spectrum of an empty tube is subtracted to each reaction spectrum, we considered that the tube properties were constant all along the tube.

Therefore, to correct these points, we tried to apply a correction with a numerical method ("Multiplicative Signal Correction" or "Standard Normal Variate") but the results were not improved. That's why an important number of latent variables are needed in this case to correct these effects. A perspective of our work would be to use glass microreactors that do not absorb and scatter light (planar microchannels) or other optical accessories for NIR analysis such as optical transmission microcells. Nevertheless, the RMSEC and RMSEP were quite low, respectively $2.34 \%$ and $3.52 \%$.

Comparatively to the batch reaction mixtures analyses performed in previous work [34], both standard errors RMSEC and RMSEP increased because the NIR spectra obtained by the reflection or the transflectance probe and measured through PFA tube show more noise than the NIR spectra acquired with the transflectance optical probe directly in the reactor. Indeed, the optical beam is altered when passing through the PFA tube due to dispersion. Noise fluctuations are obtained with different positions of the tube. It was more difficult to keep the same position between measurements with the reflection probe although a custom-made device has been used to reduce this problem. But, these results are still satisfactory because the errors on calibration and prediction are lower than 5\%. RMSEC and RMSEP are lower and therefore better in Fig. 7 
because the samples used were prepared from the same ethanol to oil molar ratio (45.4); that means the range of ethyl oleate contents obtained from one molar ratio is more limited than the range of ethyl oleate contents obtained for different molar ratios. Hence, the transflectance probe is more useful than the reflection probe both in batch systems or in microreactors.

\section{Conclusion}

The high oleic sunflower oil transesterification reaction with ethanol catalyzed by EtONa has successively been transposed from a batch reactor to a continuous microreactor device. This study showed that, in the case of ethanolysis of high oleic sunflower oil, flow chemistry processes are an excellent way for obtaining more information in less time. Moreover, two calibration models of NIR spectroscopy were developed to on-line evaluate the content of the main component (ethyl oleate) during the transesterification reaction in microreactors. Results demonstrate that NIR spectroscopy is a fast, reliable, non-pollutant and user-friendly technique to on-line determine the composition of a reaction mixture during transesterification. Analysis is facilitated as no collection or preparation is necessary. This innovative technique is appropriate to get optimal reaction parameters and collect data, more particularly at very low characteristic times.

\section{Acknowledgements}

We gratefully acknowledge the co-financial support from INRA (Institut National de la Recherche Agronomique) and the Région Midi-Pyrénées in France which enabled 
us to lead this research work in the Laboratoire de Chimie Agro-industrielle (LCA) and the Laboratoire de Génie Chimique (LGC).

\section{References}

[1] Demirbas A, Karslioglu S. Biodiesel production facilities from vegetable oils and animal fats. Energy Sources Part A 2007; 29:133-41.

[2] Encinar JM, González JF, Rodríguez-Reinares A. Ethanolysis of used frying oil. Biodiesel preparation and characterization. Fuel Process. Technol. 2007; 88:513-22.

[3] Darnoko D, Cheryan M. Kinetics of palm oil transesterification in a batch reactor. J. Am. Oil Chem. Soc. 2000; 77:1263-7.

[4] Fukuda H, Kondo A, Noda H. Biodiesel Fuel Production by Transesterification of Oils. J. Biosci. Bioeng. 2001; 92:405-16.

[5] Srivastava PK, Verma M. Methyl ester of karanja oil as an alternative renewable source energy. Fuel 2008; 87:1673-7.

[6] Sharma YC, Singh B. Development of biodiesel from karanja, a tree found in rural India. Fuel 2008; 87:1740-2.

[7] Freedman B, Pryde EH, Mounts TL. Variables Affecting the Yields of Fatty Esters from Transesterified Vegetable-Oils. J. Am. Oil Chem. Soc. 1984; 61:1638-43.

[8] Meher LC, Vidya Sagar D, Naik SN. Technical aspects of biodiesel production by transesterification - a review. Renew. Sust. Energy Rev. 2006; 10:248-68.

[9] Sharma YC, Singh B, Upadhyay SN. Advancements in development and characterization of biodiesel: A review. Fuel 2008; 87:2355-73.

[10] Marjanovic AV, Stamenkovic OS, Todorovic ZB, Lazic ML, Veljkovic VB. Kinetics of the base-catalyzed sunflower oil ethanolysis. Fuel 2010; 89:665-71.

[11] Qiu Z, Zhao L, Weatherley L. Process intensification technologies in continuous biodiesel production. Chem. Eng. Process. 2010; 49:323-30.

[12] Sun P, Wang B, Yao J, Zhang L, Xu N. Fast Synthesis of Biodiesel at High Throughput in Microstructured Reactors. Ind. Eng. Chem. Res. 2009; 49:1259-64.

[13] Wen Z, Yu X, Tu S-T, Yan J, Dahlquist E. Intensification of biodiesel synthesis using zigzag micro-channel reactors. Bioresour. Technol. 2009; 100:3054-60.

[14] Sun J, Ju J, Ji L, Zhang L, Xu N. Synthesis of Biodiesel in Capillary Microreactors. Ind. Eng. Chem. Res. 2008; 47:1398-403.

[15] Guan G, Teshima M, Sato C, Mo Son S, Faisal Irfan M, Kusakabe K, Ikeda N, Lin TJ. Twophase flow behavior in microtube reactors during biodiesel production from waste cooking oil. AIChE J. 2010; 56:1383-90.

[16] Stankiewicz AI, Moulijn JA. Process intensification: transforming chemical engineering. Chem. Eng. Prog. 2000; 96:22-34.

[17] Mittelbach M. Diesel Fuel Derived from Vegetable-Oils, V [1] - Gas-Chromatographic Determination of Free Glycerol in Transesterified Vegetable-Oils. Chromatographia 1993; 37:623-6.

[18] Knothe G. Analytical methods used in the production and fuel quality assessment of biodiesel. Trans. ASAE 2001; 44:193-200.

[19] Holcapek M, Jandera P, Fischer J, Prokes B. Analytical monitoring of the production of biodiesel by high-performance liquid chromatography with various detection methods. J. Chromatogr., A 1999; 858:13-31.

[20] Zagonel GF, Peralta-Zamora P, Ramos LP. Multivariate monitoring of soybean oil ethanolysis by FTIR. Talanta 2004; 63:1021-5.

[21] Mahamuni NN, Adewuyi YG. Fourier Transform Infrared Spectroscopy (FTIR) Method To Monitor Soy Biodiesel and Soybean Oil in Transesterification Reactions, Petrodiesel - Biodiesel Blends, and Blend Adulteration with Soy Oil. Energy Fuels 2009; 23:3773-82.

[22] Trevisan MG, Garcia CM, Schuchardt U, Poppi RJ. Evolving factor analysis-based method for correcting monitoring delay in different batch runs for use with PLS: On-line monitoring of a transesterification reaction by ATR-FTIR. Talanta 2008; 74:971-6.

[23] Sivakesava S, Irudayaraj J, Ali D. Simultaneous determination of multiple components in lactic acid fermentation using FT-MIR, NIR, and FT-Raman spectroscopic techniques. Process Biochem. 2001; 37:371-8. 
[24] Killner MHM, Rohwedder JJR, Pasquini C. A PLS regression model using NIR spectroscopy for on-line monitoring of the biodiesel production reaction. Fuel 2011; 90:3268-73.

[25] Pinzi S, Alonso F, García Olmo J, Dorado MP. Near infrared reflectance spectroscopy and multivariate analysis to monitor reaction products during biodiesel production. Fuel 2012; 92:354-9.

[26] de Oliveira IK, de Carvalho Rocha WF, Poppi RJ. Application of near infrared spectroscopy and multivariate control charts for monitoring biodiesel blends. Anal. Chim. Acta 2009; 642:217-21.

[27] Knothe G. Monitoring a progressing transesterification reaction by fiber-optic near infrared spectroscopy with correlation to ${ }^{1} \mathrm{H}$ nuclear magnetic resonance spectroscopy. J. Am. Oil Chem. Soc. 2000; 77:489-93.

[28] Monni J, Niemelä P, Alvila L, Pakkanen TT. Online monitoring of synthesis and curing of phenol-formaldehyde resol resins by Raman spectroscopy. Polymer 2008; 49:3865-74.

[29] Chen T-Y, Chao C-S, Mong K-KT, Chen Y-C. Ultrasonication-assisted spray ionization mass spectrometry for on-line monitoring of organic reactions. Chem. Commun. 2010; 46:8347-9.

[30] Chi Z, Cullum BM, Stokes DL, Mobley J, Miller GH, Hajaligol MR, Vo-Dinh T. Hightemperature vapor detection of polycyclic aromatic hydrocarbon fluorescence. Fuel 2001; 80:1819-24.

[31] Lewis AC, Roberts DJ. New Techniques for Following the Oxidation of Sodium Sulfite in MassTransfer Studies. Ind. Eng. Chem. Res. 2004; 44:183-5.

[32] Knothe G. Rapid monitoring of transesterification and assessing biodiesel fuel quality by nearinfrared spectroscopy using a fiber-optic probe. J. Am. Oil Chem. Soc. 1999; 76:795-800.

[33] Balabin RM, Safieva RZ, Lomakina EI. Gasoline classification using near infrared (NIR) spectroscopy data: Comparison of multivariate techniques. Anal. Chim. Acta 2010; 671:27-35.

[34] Richard R, Li Y, Dubreuil B, Thiebaud-Roux S, Prat L. On-line monitoring of the transesterification reaction between triglycerides and ethanol using near infrared spectroscopy combined with gas chromatography. Bioresour. Technol. 2011; 102:6702-9.

[35] Noureddini H, Zhu D. Kinetics of transesterification of soybean oil. J. Am. Oil Chem. Soc. 1997; 74:1457-63.

[36] Lanza M, Neto WB, Batista E, Poppi RJ, Meirelles AJA. Liquid-Liquid Equilibrium Data for Reactional Systems of Ethanolysis at 298.3 K. J. Chem. Eng. Data 2008; 53:5-15.

[37] Wright H, Segur J, Clark H, Coburn S, Langdon E, DuPuis R. A report on ester interchange. J. Am. Oil Chem. Soc. 1944; 21:145-8.

[38] Ma F, Hanna MA. Biodiesel production: a review. Bioresour. Technol. 1999; 70:1-15.

\section{Figure captions:}

Table 1: Ethyl ester contents obtained by GC-FID for transesterification reactions carried out in batch or microreactors $(1 \mathrm{wt} \%$ of EtONa and $0.08 \mathrm{wt} \%$ of water content in ethanol were used in all experiments).

Table 2: External validation results for the prediction of ethyl ester content using different pre-processing methods.

Fig. 1: Experimental set-up of the transesterification reaction carried out in a microreactor. 
Fig. 2: Pictures and schemes of the a) reflection probe and b) transflectance probe used in the experimental set-up of Fig. 1.

Fig. 3: Ethyl oleate content in the reaction mixtures at $70{ }^{\circ} \mathrm{C}$ according to the reaction time for three ethanol to oil molar ratios in a $1 \mathrm{~L}$-batch reactor.

Fig. 4: Ethyl oleate content in the reaction mixtures at $65^{\circ} \mathrm{C}$ according to the reaction time for various ethanol to oil molar ratios in microreactors.

Fig. 5: Composition of reaction mixture during transesterification reaction in microreactors for an ethanol to oil molar ratio of 9.0 at $65^{\circ} \mathrm{C}$.

Fig. 6: Correlation between ethyl oleate contents obtained by GC-FID and through the FT-NIR model for different ethanol to oil molar ratio at $65^{\circ} \mathrm{C}$ (data acquired with the reflection probe: 44 samples for calibration and 25 for prediction).

Fig. 7: Correlation between ethyl oleate contents obtained by GC-FID and through the FT-NIR model for the same ethanol to oil molar ratio at $65{ }^{\circ} \mathrm{C}$ (data acquired with the transflectance probe: 40 samples for calibration and 21 for prediction). 
Table 1

\begin{tabular}{|c|c|c|c|c|c|c|c|c|c|}
\hline \multicolumn{4}{|c|}{$\begin{array}{c}\text { EE CONTENT (\%) IN } \\
\text { BATCH }\left(70^{\circ} \mathrm{C}\right)\end{array}$} & \multicolumn{6}{|c|}{$\begin{array}{c}\text { EE CONTENT }(\%) \text { IN } \\
\text { MICROREACTOR }\left(65^{\circ} \mathrm{C}\right)\end{array}$} \\
\hline \multirow{2}{*}{$\begin{array}{c}\text { Reaction } \\
\text { time } \\
\text { (min) }\end{array}$} & \multicolumn{3}{|c|}{$\begin{array}{l}\text { Ethanol to oil } \\
\text { molar ratio }\end{array}$} & \multirow{2}{*}{$\begin{array}{c}\text { Reaction } \\
\text { time } \\
\text { (min) }\end{array}$} & \multicolumn{5}{|c|}{$\begin{array}{l}\text { Ethanol to oil } \\
\text { molar ratio }\end{array}$} \\
\hline & 3.0 & 6.0 & 9.0 & & 6.0 & 9.0 & 16.2 & 22.7 & 45.4 \\
\hline & & & & 0.79 & 18.6 & 14.0 & 8.1 & 5.7 & 6.5 \\
\hline & & & & 1.57 & 42.2 & 39.8 & 60.6 & 42.3 & 25.9 \\
\hline 3 & 54.1 & 92.3 & 88.1 & 2.36 & 60.0 & 55.5 & 83.7 & 77.1 & 75.0 \\
\hline 6 & 61.7 & 94.9 & 92.6 & 3.14 & 66.5 & 66.9 & 85.7 & 87.0 & N/A \\
\hline 10 & 64.8 & 96.2 & 94.2 & 3.93 & 72.7 & 78.8 & 89.7 & 92.3 & 96.3 \\
\hline 15 & $\mathrm{~N} / \mathrm{A}$ & 97.0 & $\mathrm{~N} / \mathrm{A}$ & 4.71 & 76.0 & 85.6 & 91.4 & 92.8 & N/A \\
\hline 20 & 69.3 & 98.0 & 95.1 & 5.50 & 76.6 & 87.7 & 87.3 & 93.8 & 96.7 \\
\hline 30 & $\mathrm{~N} / \mathrm{A}$ & 98.5 & $\mathrm{~N} / \mathrm{A}$ & 6.68 & 79.7 & 89.7 & 92.7 & 92.1 & 96.8 \\
\hline 40 & $\mathrm{~N} / \mathrm{A}$ & 99.2 & $\mathrm{~N} / \mathrm{A}$ & 7.85 & 81.4 & 90.5 & 92.8 & 93.5 & 96.4 \\
\hline 50 & $\mathrm{~N} / \mathrm{A}$ & 99.4 & $\mathrm{~N} / \mathrm{A}$ & 9.82 & 83.1 & 91.6 & 93.0 & 93.5 & N/A \\
\hline \multirow[t]{3}{*}{60} & 75.3 & 99.5 & 94.4 & 11.78 & 82.6 & 91.8 & 92.2 & 94.4 & 96.2 \\
\hline & & & & 13.74 & 85.1 & 92.0 & 92.8 & 93.5 & $\mathrm{~N} / \mathrm{A}$ \\
\hline & & & & 15.71 & $\mathrm{~N} / \mathrm{A}$ & 92.3 & 90.2 & 93.0 & 96.0 \\
\hline
\end{tabular}

N/A : Not Available 
Table 2

\begin{tabular}{|c|c|c|c|c|c|}
\hline $\begin{array}{c}\text { DATA } \\
\text { TREATMENT }\end{array}$ & Parameter & $\begin{array}{c}\text { Baseline } \\
\text { correction } \\
\mathbf{a}\end{array}$ & $\begin{array}{c}{ }^{a}+S G \\
\text { smoothing } \\
b\end{array}$ & $\underset{\mathbf{c}}{\stackrel{b}{\mathbf{b}}+}$ & $\begin{array}{c}\text { c Mean- } \\
\text { centering } \\
+ \\
\text { variance } \\
\text { scaling } d \\
\end{array}$ \\
\hline \multirow{4}{*}{$\begin{array}{l}\text { Reflection probe } \\
\text { (44 samples for } \\
\text { calibration and } \\
25 \text { for prediction) }\end{array}$} & $\begin{array}{c}\text { Latent } \\
\text { variables }\end{array}$ & 5 & 6 & 5 & 5 \\
\hline & $\mathrm{R}^{2}$ & 0.94335 & 0.90729 & 0.92148 & 0.98471 \\
\hline & RMSEC & 7.81 & 9.93 & 9.18 & 4.08 \\
\hline & RMSEP & 19.20 & 8.58 & 8.23 & 4.10 \\
\hline \multirow{4}{*}{$\begin{array}{c}\text { Transflectance } \\
\text { probe ( } 40 \\
\text { samples for } \\
\text { calibration and } \\
21 \text { for prediction) }\end{array}$} & $\begin{array}{c}\text { Latent } \\
\text { variables }\end{array}$ & 7 & 9 & 9 & 9 \\
\hline & $\mathrm{R}^{2}$ & 0.95992 & 0.928 & 0.94082 & 0.98289 \\
\hline & RMSEC & 3.56 & 4.74 & 4.3 & 2.34 \\
\hline & RMSEP & 7.04 & 5.52 & 5.27 & 3.52 \\
\hline
\end{tabular}

${ }^{a}$ Obtained using as reference the region between the wavenumbers of $10,000-9000 \mathrm{~cm}^{-1}$.

${ }^{\mathrm{b}}$ Savitzky-Golay smoothing obtained by a $3^{\text {rd }}$ order polynomial using 45 and 41 points window for respectively the spectra obtained by the reflection and transflectance probe.

${ }^{\mathrm{c}}$ First derivative for same points window.

${ }^{\mathrm{d}}$ Mean centering calculates the average spectrum and subtracts it from each calibration spectrum. With variance scaling, the standard deviation of the intensity values of each $\mathrm{X}$-axis location in the calibration spectra is obtained dividing each data point in each calibration spectrum by its estimated standard deviation. 
Figure 1

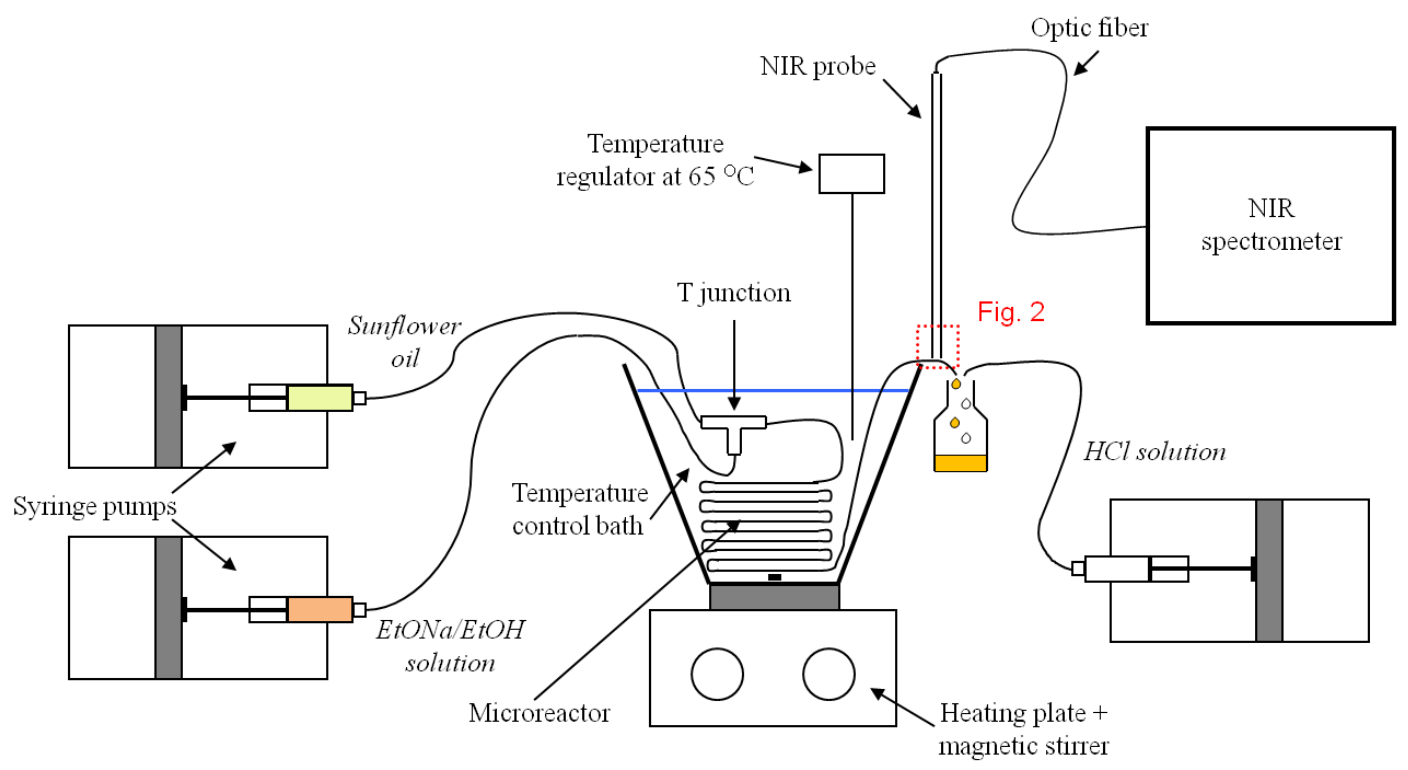


Figure 2

a)

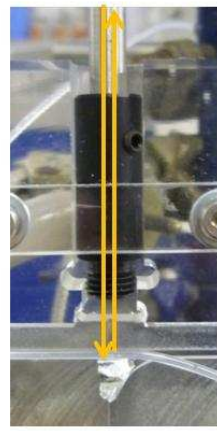

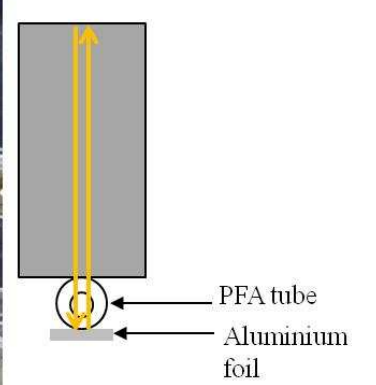

b)

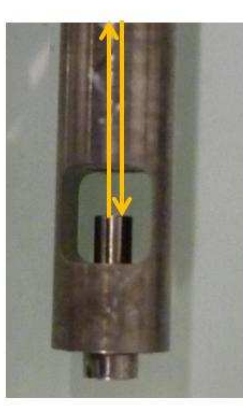

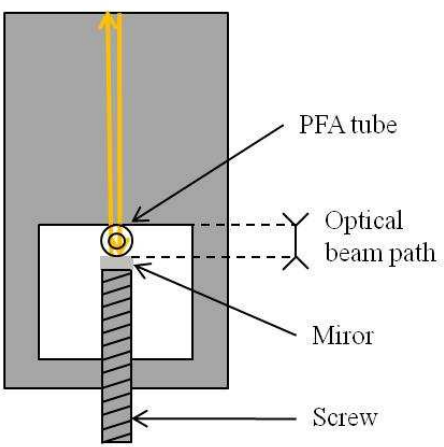


Figure 3

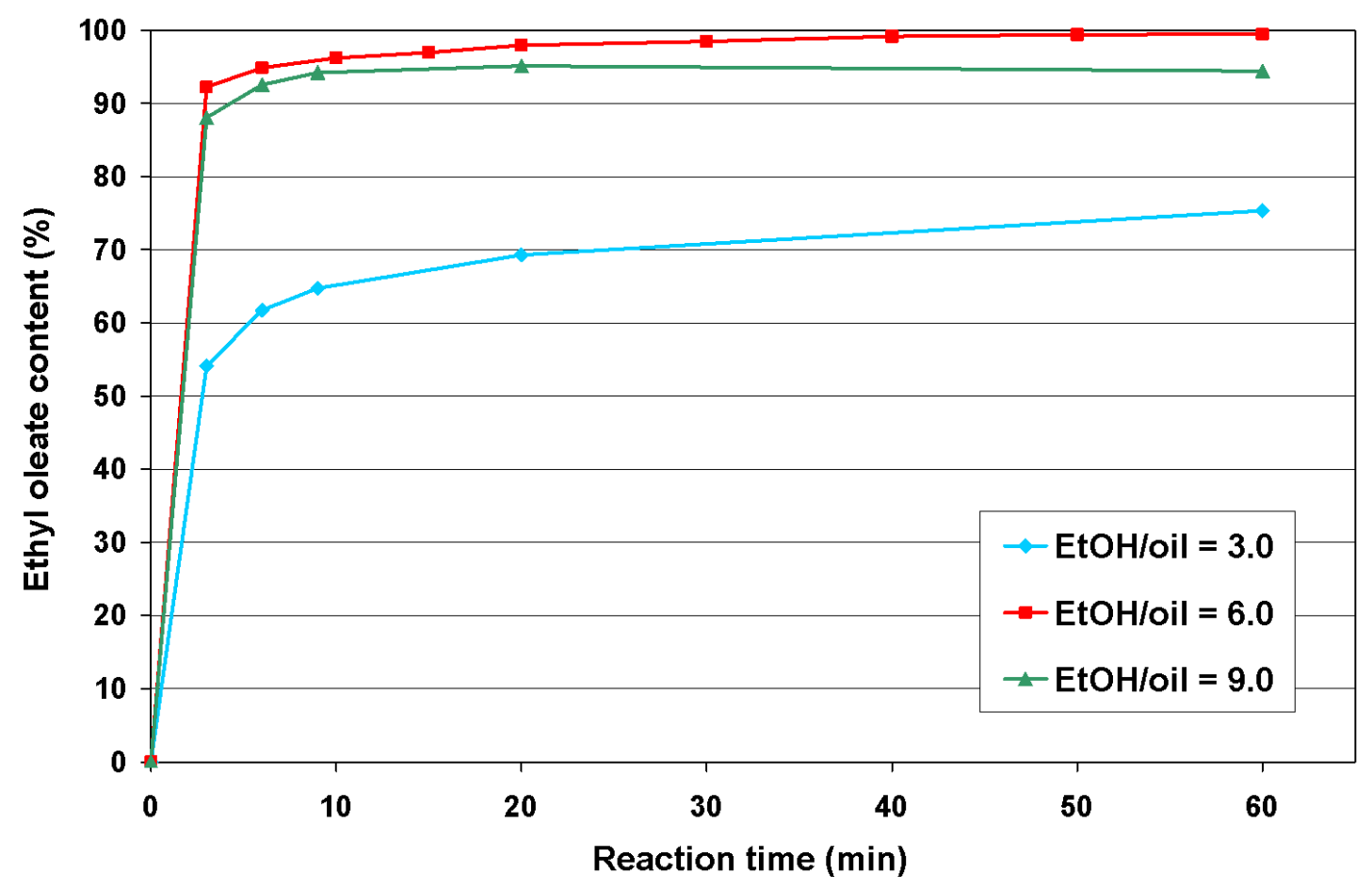


Figure 4

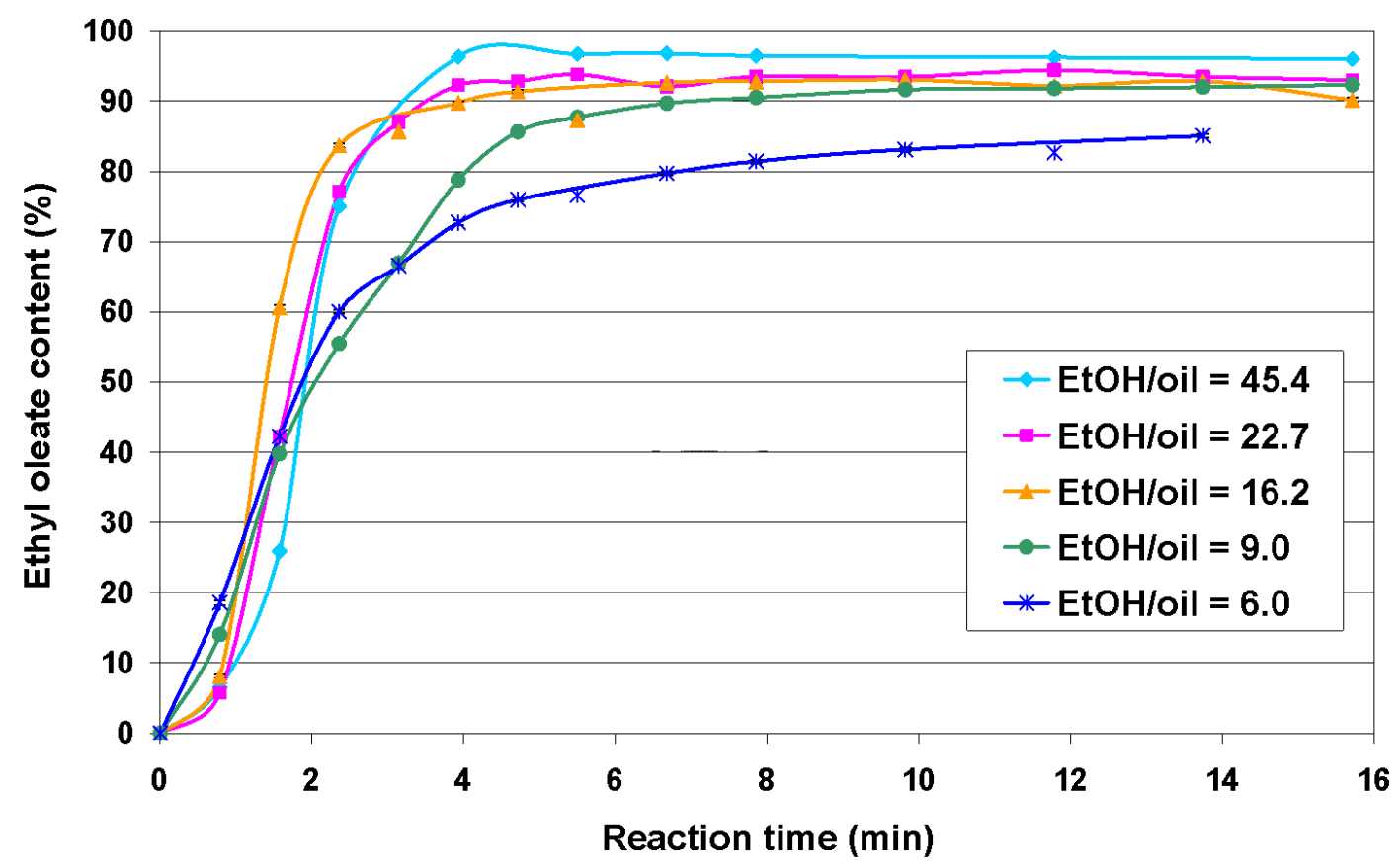


Figure 5

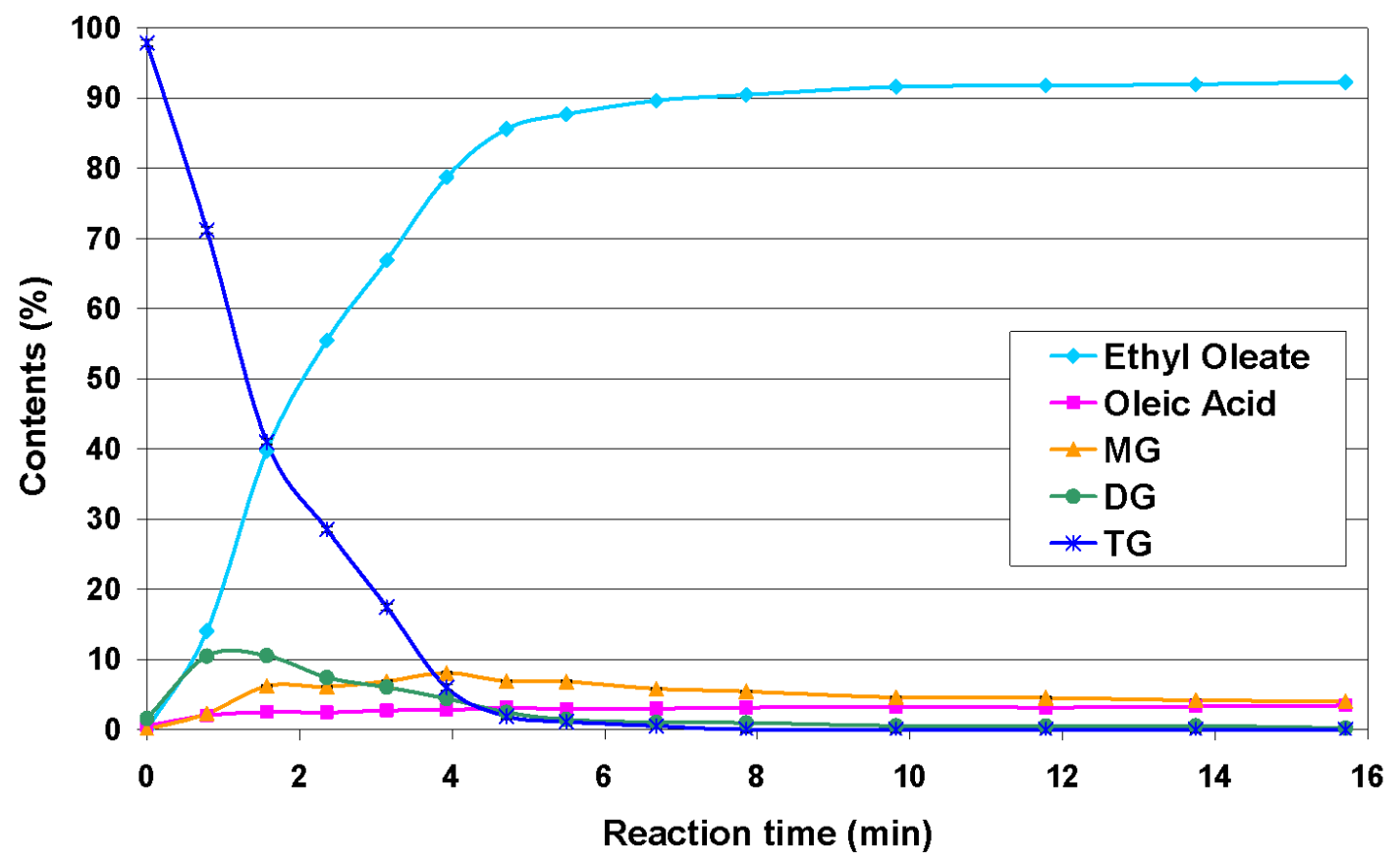


Figure 6

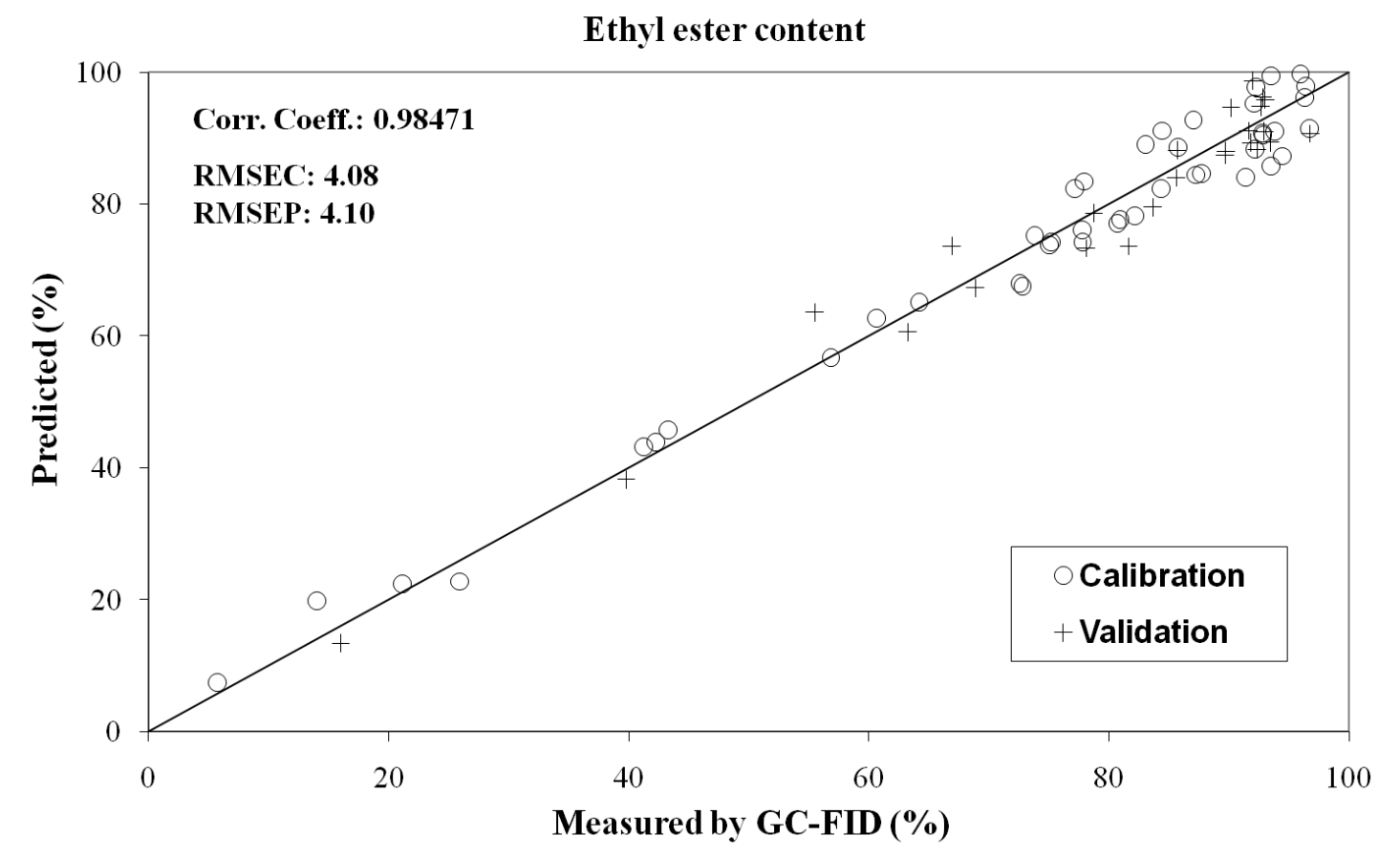




\section{Figure 7}

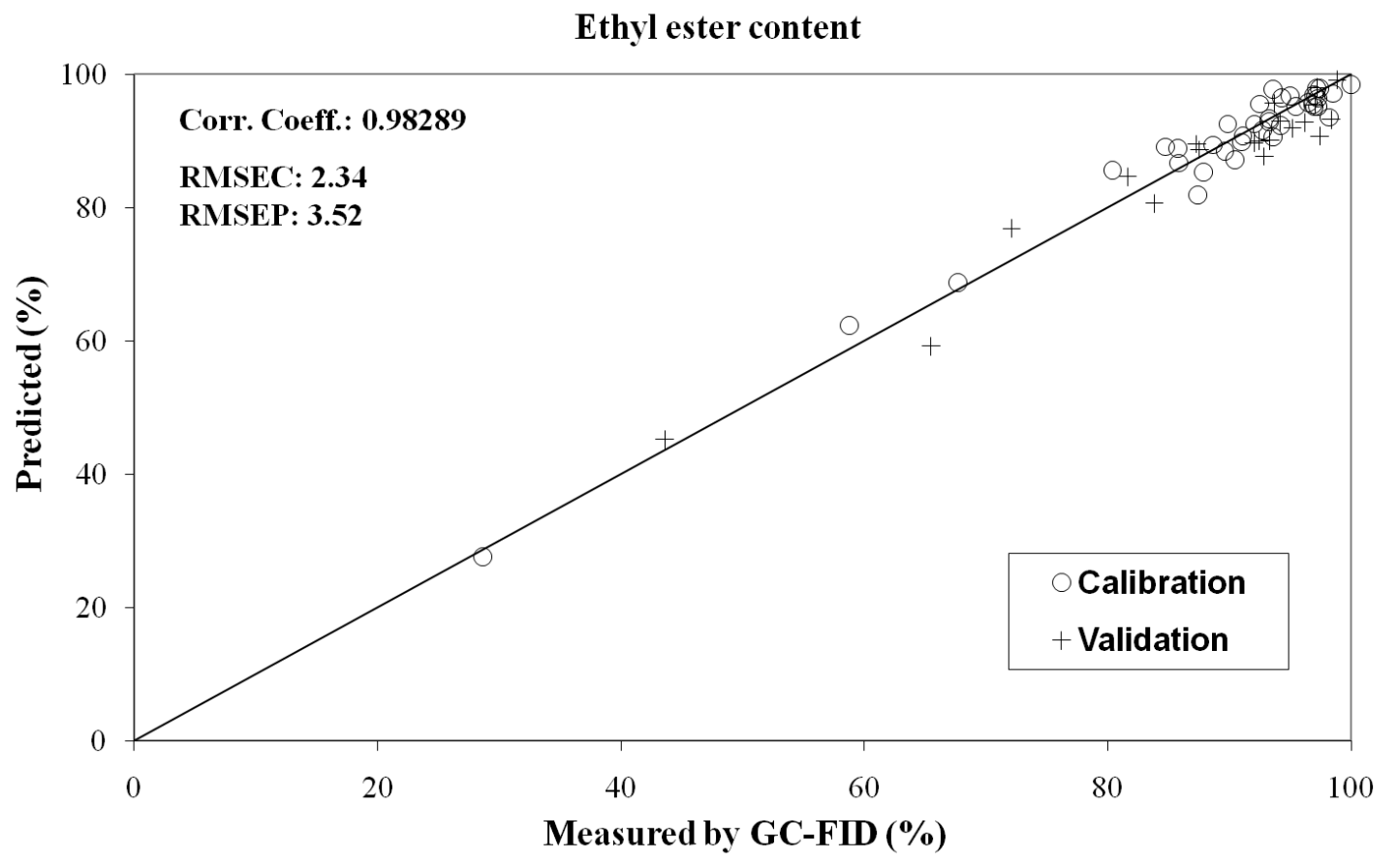

